\title{
Confluindo gênero e educação popular por meio de uma pesquisa-ação para a abordagem do tabagismo feminino em contextos de vulnerabilidade social ${ }^{*}$
}

Márcia Terezinha Trotta Borges ${ }^{1}$

Regina Helena Simões Barbosa²

BORGES, M.T.T.; BARBOSA, R.H.S. Converging gender and popular education through action research to address female smoking within contexts of social vulnerability. Interface (Botucatu), v.17, n.46, p.601-14, jul./set. 2013.

This paper presents the results from action research that addressed female smoking in community spaces. The proposal originated from dialogue between the conceptual and methodological fields relating to feminism and popular education and aimed to pick out and gain an understanding of subjective and objective issues relating to female smoking, both in the family and in the social community spheres. In this action research, six women who were former smokers and were living in a community in Rio de Janeiro, Brazil, were trained to develop an educational process that reached women, men, adolescents and children in the form of dialogue and participation. The results revealed how to build shared knowledge on health, resulting from integration of academic and popular knowledge through dialogic educational praxis, thereby confirming the potential of this proposal for coping with female smoking in such contexts.

Keywords: Smoking. Gender identity. Popular education. Action research.

\begin{abstract}
O artigo apresenta resultados gerados por uma pesquisa-ação (PA) que abordou o tabagismo feminino em espaços populares. A proposta originou-se do diálogo entre os campos conceituais e metodológicos oriundos do feminismo e da educação popular, e teve por objetivo captar e compreender questões subjetivas e objetivas do universo feminino relacionadas ao fumar, tanto no âmbito familiar quanto no sociocomunitário. A PA capacitou seis moradoras de uma comunidade do Rio de Janeiro, Brasil, ex-fumantes, para desenvolveram um processo educativo que alcançou, de forma dialogada e participativa, mulheres, homens, jovens e crianças. Os resultados revelam como se constrói, por meio da práxis educativa dialógica, um conhecimento compartilhado sobre a saúde que resulta da integração entre saber acadêmico e saber popular, confirmando o potencial desta proposta de enfrentamento do tabagismo feminino nos contextos populares.

Palavras-chave: Hábito de fumar. Identidade de gênero. Educação popular. Pesquisa-ação.

- Elaborado com base em (Barbosa, Borges, 2009-2011); pesquisaação aprovada pelos Comitês de Ética em Pesquisa da Secretaria Municipal de Saúde e Defesa Civil do Rio de Janeiro (SMSDC-RJ) e do Instituto Nacional de Câncer (INCA/MS), e registrada no SIGMA/ UFRJ, com chancela financeira da Organização

Pan-Americana de Saúde (OPAS).

${ }^{2}$ Instituto de Estudos em Saúde Coletiva, Universidade Federal do Rio de Janeiro. Praça Jorge Machado Moreira, 100, Cidade Universitária. Rio de Janeiro, RJ, Brasil. 21941-598.

marciatrotta@gmail.com
\end{abstract}




\section{Introdução}

O artigo apresenta e discute os resultados gerados por uma pesquisa-ação (PA) que abordou o tabagismo feminino em um enfoque crítico de gênero entre mulheres de comunidades populares. A proposta conceitual e metodológica adotada pretendeu estabelecer um diálogo interdisciplinar entre o campo da educação popular em saúde e o tabagismo feminino, visando contribuir para as estratégias de enfrentamento deste complexo e grave problema de saúde pública.

Os indicadores epidemiológicos que apontam, em nível global, o crescimento do tabagismo entre a população feminina (Shafey et al., 2009), particularmente a de baixa renda e escolaridade, motivaram a elaboração e implementação desta PA em uma comunidade popular da cidade do Rio de Janeiro. O objetivo central foi captar e compreender questões subjetivas e objetivas do universo feminino relacionadas ao fumar, tanto no âmbito familiar como sociocomunitário, visando contribuir tanto para a elaboração de um modelo de intervenção educativa construído com e para mulheres que vivem em espaços populares, quanto para a produção de conhecimentos que resultam de um processo dialógico e relacional. Para tal, mulheres ex-fumantes, oriundas de um grupo de tratamento de tabagismo de um Centro Municipal de Saúde localizado na comunidade eleita para o estudo, foram recrutadas e capacitadas, através da metodologia da educação popular e da pedagogia feminista, como multiplicadoras de ações educativas voltadas para a prevenção do tabagismo feminino entre mulheres integrantes de suas redes sociofamiliares e comunitárias.

Os referenciais teóricos, que embasaram e sustentaram esta experiência no campo da prevenção do tabagismo, apoiaram-se em: um enfoque crítico de gênero (Giffin, 2002; Simões-Barbosa, 2001a; Brito, 2000; Castro, 2000; Kergoat, 1996; Saffioti, 1992), no modelo educativo oriundo da pedagogia da pergunta que originou o campo da Educação Popular em Saúde -, e na pedagogia feminista oriunda do movimento de mulheres, tal como consubstanciado no Programa de Assistência Integral à Saúde da Mulher (PAISM) (Simões Barbosa, 2001b; Freire, 1996; Giffin, 1995; Valadares, Sanches, Giffin, 1987). Os resultados gerados neste - e através deste - processo educativo, que estabeleceu um diálogo entre o saber acadêmico e o saber popular, confirmam o potencial desta proposta para o enfrentamento do tabagismo feminino em espaços populares e sua multiplicação em contextos sociocuturais semelhantes.

\section{Cenário do tabagismo no mundo e no Brasil: desafios para a Saúde Pública e a Educação e Saúde}

Diversos são os fatores que contribuem para o desencadeamento, a manutenção e a permanência de certos hábitos que as sociedades adquirem ao longo de sua história. Longe de ser apenas um 'hábito', o fumar está presente de forma direta no cotidiano de mais de um bilhão de pessoas no mundo (Shafey et al., 2009; World Health Organization, 2009), além de um significativo contingente de pessoas que são afetadas de forma indireta, através do fumo passivo. Em função de sua íntima relação com as inúmeras doenças relacionadas ao seu consumo, o cigarro protagoniza uma relação antagônica de prazer e repulsa, sendo um importante fator de risco para seis dentre as oito principais causas de morte no mundo (Shafey et al., 2009). Reconhecido desde 1992 pela Organização Mundial de Saúde (OMS) como uma dependência ${ }^{3}$, o fumo é responsável por, aproximadamente, seis milhões de mortes/ano em todo o planeta, sendo que $72 \%$ ocorrem nos países em desenvolvimento (Shafey et al., 2009).
${ }^{3} \mathrm{O}$ tabagismo foi

classificado no grupo dos transtornos mentais e de comportamento decorrentes do uso de substâncias psicoativas, na décima revisão da Classificação Internacional de Doenças (CID) da OMS, categoria F17.2. 
Os indicadores epidemiológicos apontam, em nível global, para o crescimento do tabagismo entre a população feminina, particularmente a de baixa renda e escolaridade, sendo que, atualmente, as mulheres e os jovens são o público-alvo preferencial da indústria fumageira (Shafey et al., 2009), o que confirma os processos de juvenilização, pauperização e feminização do tabagismo em curso (Borges, Barbosa, 2009). Como demonstrado em nossas pesquisas, o tabagismo feminino é um problema complexo e que envolve várias dimensões de vida - objetivas e subjetivas - das mulheres, demandando, portanto, uma abordagem de gênero para a compreensão ampliada do fenômeno em suas várias dimensões (Borges, Barbosa, 2009; Borges, Simões-Barbosa, 2008; Borges, 2007).

No Brasil, a política para o controle do tabaco vem apresentando resultados positivos e mostrando-se eficiente em função de uma série de medidas tomadas em diferentes setores, como: a proibição das propagandas, as campanhas pontuais e a oferta de tratamento e medicamentos na rede pública, entre outros. Os inquéritos populacionais indicam avanços claros na política de controle do uso do tabaco (Brasil, 2008), mas essas estratégias, a despeito dos excelentes resultados alcançados, esbarraram nos seus limites, o que exige novas propostas inovadoras que alcancem, em especial, as populações feminina e jovem (Wunsch Filho et al., 2010; Borges, Barbosa, 2009; Borges, Simões-Barbosa, 2008; Borges, 2007). Isto nos coloca frente ao desafio de construir e implementar metodologias de intervenção para a prevenção e estímulo à cessação do tabagismo, que abarquem as diversas dimensões de vida dos indivíduos e se direcionem, preferencialmente, para as populações que vivem em contextos de vulnerabilidade social, estimulando a adoção de novas posturas e valores de vida que possam, inclusive, repercutir positivamente sobre a saúde e a qualidade de vida de suas famílias e comunidades.

Como amplamente preconizado, as ações de enfrentamento deste complexo problema devem envolver maior mobilização e participação social. Embora no campo da prevenção e promoção da saúde os modelos educativos de cunho participativo já sejam adotados há algumas décadas, principalmente pelo campo da Educação Popular em Saúde (EPS), sua articulação com o tema do tabagismo é recente e, como pretendemos demonstrar, muito promissora.

\section{Educação Popular e Saúde: \\ desafios para a construção compartilhada do conhecimento}

As premissas epistemológicas, políticas e pedagógicas da educação popular partem do reconhecimento do valor do saber popular na produção de um 'conhecimento ampliado', resultante do diálogo entre o saber cientifico e o saber popular, e radicalmente comprometido com uma práxis voltada para a transformação da realidade de vida e saúde da população. De acordo com Carvalho, Acioli e Stotz, essa 'construção compartilhada do conhecimento' " [...] implica um processo comunicacional e pedagógico entre sujeitos de saberes diferentes convivendo em situações de integração e cooperação, que envolve o relacionamento entre pessoas ou grupos com experiências diversas, interesses, desejos, motivações coletivas" (Carvalho, Acioli, Stotz, 2001, p.103).

Para embasar a discussão da PA, nos apoiaremos nas premissas conceituais e metodológicas da Educação Popular em Saúde (EPS), em diálogo com a proposta educativa oriunda do movimento de mulheres, sendo esses dois referenciais, a nosso ver, imprescindíveis para fundamentar um modelo educativo em saúde transformador, que incorpore a complexidade de questões socioculturais que perpassam o processo saúde-doença e, em especial, o tabagismo.

O diálogo entre os serviços de saúde e os movimentos sociais e populares, quando ocorre, tem se revelado muito fecundo. Nesta relação, a EPS vem se afirmando como uma proposta pedagógica e uma práxis educativa que busca construir uma relação horizontal e dialógica entre sujeitos sociais distintos, o que geralmente resulta em ações com grande potencial de transformação. O educador Paulo Freire, através de suas ideias e experiências pioneiras na área de educação, iniciadas no Brasil no início dos anos cinquenta, é o eixo de referência deste enfoque e, correlatamente, desta práxis pedagógica. $\mathrm{O}$ ponto de partida deste processo educativo é o diálogo e a troca entre o saber técnico-científico e a cultura popular, o que já sinaliza para uma escolha em se trabalhar com as classes populares, na perspectiva de compromisso com a justiça social. Apesar do movimento liderado por Freire ter recebido, a partir da década de 1970, a adesão de muitos profissionais de saúde, ainda esbarra, nos dias atuais, na 
dificuldade de os serviços de saúde superarem as práticas hierarquizadas e verticais que marcam o modelo hegemônico de educação e saúde (Valla, 2011; David, Acioli, 2010; Freire, 2009; Vasconcelos, 2007, 2004, 1998; Freire, 1996; Freire, Faundez, 1985).

A articulação do campo da EPS ao tabagismo feminino está calcada em alguns pressupostos de Freire que embasaram a PA e que serão aqui brevemente sinalizados. Em primeiro lugar, destaca-se o papel da 'conscientização', um processo que abre caminho para a expressão das insatisfações sociais, permitindo alargar a compreensão dos mecanismos que perpetuam as situações de injustiça e desigualdade, para denunciá-las (Freire, 2009). O trabalho com a unidade dialética da subjetividade/ objetividade gera reflexão problematizadora e ação sobre uma dada realidade, visando transformá-la. Esta pedagogia permite, portanto, a reflexão crítica sobre as situações concretas de vida, levando o sujeito ao engajamento na luta por sua libertação, luta que é forjada com ele, e não para ele (Freire, 2009). Outro ponto importante é a forma como o processo educativo em geral ocorre. Na perspectiva de uma pedagogia emancipadora, educador e educando são ambos sujeitos de conhecimento, ensinam e aprendem e, juntos, vão desvelando o mundo e comprometendo-se com sua transformação através de uma práxis pedagógica transformadora. Neste sentido, relativiza a importância do saber formal, acadêmico, e valoriza os conhecimentos adquiridos nas experiências cotidianas de vida e nas diversidades culturais, o que faz pressupor uma relação de permanente diálogo e a postura do "saber escutar". O aprendizado cognitivo, apesar de ser fundamental, transforma-se ao agregar as dimensões afetivas, culturais, morais, coletivas e históricas no processo permanente de ensinar-aprender (Freire, 2009). Portanto, o reconhecimento de uma 'comunidade ampliada' no processo de produção do conhecimento representa um avanço epistemológico e pedagógico.

Os saberes empíricos da população são construídos e elaborados a partir de suas experiências concretas de vida e são diversos das vivências do educador/ facilitador, já que se encontram atravessadas por diferenciais culturais e socioeconômicos; assim, só poderão emergir - e romper 'muros invisíveis' - através de uma relação de mútua confiança, em que ambos os sujeitos colocam-se abertos à contribuição do outro (Valla, 2011; Freire, 2009; Freire, Faundes, 1985).

Podemos identificar profundas afinidades entre o campo da EPS e a pedagogia gestada pelo/ no movimento de mulheres e, posteriormente, incorporada ao Programa de Assistência Integral à Saúde da Mulher (PAISM), definido como modelo de assistência à saúde das brasileiras desde 1983 (Simões Barbosa, Giffin, 2007; Simões-Barbosa, 2001a; Costa, Aquino, 2000; Osis, 1998; Giffin, 1995; Xavier, Ávila, Correa, 1989; Valadares, Sanches, Giffin, 1987). Esta proposta aponta para uma relação educativa calcada no diálogo e respeito entre profissionais de saúde e usuárias, em que todas compartilham e acolhem as experiências das outras, guardando profundo respeito às diversidades socioculturais. Tal concepção tem, como eixo, a promoção da cidadania feminina, assumindo que as mulheres devem ser sujeitos de sua vida, corpo e saúde. Assim, a perspectiva de gênero e a pedagogia da libertação almejam construir, através das práticas educativas reflexivas e problematizadoras, caminhos para profundas transformações nas relações sociais, o que inclui as relações entre homens e mulheres. Ambas propõem um caminho pedagógico que passa, essencialmente, pelo compromisso com a promoção da justiça e da igualdade em todos os âmbitos (Simões Barbosa, Giffin, 2007; SimõesBarbosa, 2001a; Costa, Aquino, 2000; Osis, 1998; Giffin, 1995; Xavier, Ávila, Correa, 1989; Valadares, Sanches, Giffin, 1987).

Partindo desses pressupostos, o projeto de PA propôs-se a conhecer a complexidade do problema do tabagismo feminino, entre mulheres de camadas populares, de forma participativa e dialogada, buscando elaborar, coletiva e solidariamente, estratégias educativas de enfrentamento deste problema. A seguir, apresentaremos os fundamentos conceituais da PA, tal como adotada neste projeto.

\section{Pesquisa-ação: uma estratégia promissora de enfrentamento do tabagismo feminino}

A pesquisa-ação (PA) como alternativa de construção do conhecimento surgiu nos anos 1960/1970 a partir do compromisso de cientistas sociais e educadores com os setores populares. Reason (1994) identificou várias vertentes de pesquisas participativas, por ele nomeadas como "pesquisa do novo 
paradigma", que incorporam uma visão de mundo em que os seres humanos são "co-criadores da sua realidade". Apesar da variação nas abordagens, todas apontam as experiências do cotidiano como âmbito de transformação através de um processo reflexivo e problematizador, além da inseparabilidade entre conhecimento e ação. A educação libertadora de Paulo Freire é apontada como uma das fontes pioneiras deste tipo de proposta de construção do conhecimento (Giffin, Simões-Barbosa, 2009; Reason, 1994).

Assim, a escolha da PA para produzir conhecimentos inovadores no campo do tabagismo feminino em comunidades populares justificou-se por esta abordagem se apoiar na participação ativa de agentes sociais que buscam alcançar melhores condições de vida e saúde para si, suas famílias e comunidade. Além disso, a PA sela compromissos ético-políticos entre pesquisadores e população, na busca de novas formas de pensar e agir sobre a qualidade de vida e a saúde no plano coletivo, sendo que os conhecimentos construídos a partir dessa experiência têm grande potencial para subsidiar estratégias educativas baseadas nas reais necessidades da população.

Sendo o tabagismo um problema de saúde que pressupõe uma "mudança de comportamento", geralmente preconizada através de práticas educativas verticalizadas e normativas que desconsideram os aspectos subjetivos, culturais e os modos de vida envolvidos na experiência histórica e cotidiana dos atores sociais, os modelos educativos de cunho participativo, que envolvem a população-alvo, na elaboração, implementação e execução das ações educativas, podem ser estratégicos para a prevenção e promoção da saúde, especialmente no caso do tabagismo. Assim, neste projeto, a metodologia da PA buscou diminuir o fosso que separa as ações de profissionais de saúde e população, rompendo com a visão vertical e autoritária do processo de produção e transmissão do conhecimento, permitido novas teorizações a partir da experiência e da ação, duas categorias essenciais neste enfoque metodológico.

\section{Entrando em campo: a formação das multiplicadoras}

A PA se iniciou com a inserção da equipe em um Centro Municipal de Saúde (CMS), instituição que sediou o processo de pesquisa e intervenção, escolhido por suas características favoráveis ao desenvolvimento da proposta, tais como: ter um programa de tabagismo bem estruturado e ativo, estar conectado a um Programa de Saúde da Família (PSF), e ser local de fácil acesso e mobilidade para a equipe pesquisadora.

Baseado em uma metodologia ancorada no processo de reflexão, problematização, conscientização e ação, o projeto foi desenvolvido em duas fases: operacional, de cunho educativo e de trabalho de campo, e outra, de pesquisa acadêmica, ambas ocorrendo simultânea e articuladamente.

Apresentaremos, a seguir, uma 'descrição interpretada' do processo educativo, que inclui desde o recrutamento e capacitação das multiplicadoras até a elaboração coletiva de um programa de intervenção - naquilo que denominamos 'construção compartilhada do conhecimento' (Carvalho, Acioli, Stotz, 2001) - e sua implementação na comunidade.

Para a formação do grupo de multiplicadoras, foram recrutadas e selecionadas seis mulheres exfumantes, oriundas do programa de tratamento do tabagismo do referido CMS. O grupo foi constituído por mulheres adultas, com filhos (e, algumas, netos), com baixa escolaridade e qualificação profissional, portadoras de histórias de vida marcadas por privações e perdas, mas, também, por lutas e conquistas. Todas apresentavam histórias de casamentos e separações e sobreviviam, à época do projeto, da renda gerada pelo salário dos maridos; apenas uma delas se sustentava através da renda obtida com seu salão de beleza. No entanto, todas já haviam contribuído com a subsistência familiar em algum momento de suas vidas, trabalhando como diaristas e/ou outras modalidades de trabalho exercido no domicílio. A maioria não tinha projetos de vida para si próprias e não acreditava na possibilidade de se realizarem através do trabalho, como ressalvado por Vaidosa: "Aqui [no local em que vive], passou dos 40 anos, já não tem valor: não serve para trabalhar, estudar..."

A fase operacional do projeto desenvolveu-se em três etapas distintas: a capacitação, o (re)conhecimento da própria comunidade e a intervenção educativa propriamente dita. Na primeira etapa, de capacitação das multiplicadoras, a equipe, inicialmente, apresentou e debateu com o grupo a proposta de trabalho, que foi dialogada e remodelada durante todo o percurso. Previstas para durar 
quatro meses, as oficinas de capacitação ocorriam duas vezes por semana, com quatro horas de duração cada. Destacamos aqui a importância de um tempo longo, de quatro horas, para a realização das oficinas, o que se diferencia radicalmente das usuais 'palestras', geralmente voltadas para a transmissão vertical de conhecimentos e com pouco espaço para reflexão, debate e, especialmente, elaboração (objetiva e subjetiva) dos novos conhecimentos adquiridos. Na medida em que trabalhávamos questões sensíveis e, por vezes, delicadas, era necessário o tempo para o acolhimento, a reflexão e a busca coletiva de caminhos, respostas e insights. Mas não só para estas questões o tempo se fazia necessário: a reflexão sobre identidades e relações de gênero, remetendo às próprias experiências de vida, sempre perpassadas por emoções, também exige tempo - especialmente entre mulheres que não tinham tido, até então, muitas oportunidades para refletir criticamente sobre suas vidas. Esses temas, como sabemos, são altamente mobilizantes e, em muitos momentos, a equipe precisou ter sensibilidade e solidariedade para acolher e trabalhar as inúmeras experiências e sentimentos que afloravam.

Inicialmente, trabalhou-se o processo de grupalização-mediante dinâmicas, jogos e rodas de conversa - quando o grupo identificou, fortaleceu e consolidou os vínculos e valores éticos que norteariam o trabalho: o compromisso, a confiança e o sigilo, entre outros. Também foram sendo estruturados, de forma dialogada e compartilhada, os conteúdos do programa de capacitação em torno dos eixos temáticos gênero e tabagismo, ambos intensamente trabalhados no transcurso das oficinas. Algumas atividades de sensibilização foram realizadas de forma a propiciar um início de reflexão e trocas sobre as vivências da experimentação do fumar.

Assim, o programa relacionado ao tema do tabagismo foi sendo elaborado pelas multiplicadoras e equipe a partir das sugestões do grupo e respondendo aos seus interesses. A fala de uma multiplicadora expressa a forma como perceberam a capacitação: "A coordenadora não trouxe livro pra gente estudar, foram as nossas histórias, nossas vidas que construiu tudo o que a gente aprendeu" (Loira4).

Quanto aos conteúdos de gênero, trabalhados simultânea e articuladamente ao tema tabagismo, estes gravitavam em torno do eixo 'o que é ser mulher', em relação com o corpo e a saúde. A reflexão de gênero tanto se dava em torno das suas próprias vivências e percepções como, também, se ancorava em conhecimentos e informações sobre a situação mais ampla das mulheres no nosso país e no mundo, de forma a alargar a compreensão das multiplicadoras para além de seu cotidiano. Houve certa dificuldade inicial das mulheres em se engajarem nas oficinas de reflexão, possivelmente devido ao 'estranhamento' de questões tão naturalizadas na nossa cultura e à falta de familiaridade com a exposição de 'questões mais íntimas'. Mas, no decorrer das oficinas, as mulheres foram gradativamente compartilhando suas (muitas vezes difíceis) experiências de vida, fortalecendo os vínculos de solidariedade e confiança entre as integrantes do grupo, tanto da equipe quanto das multiplicadoras. As oficinas eram elaboradas de forma a: estimular as participantes a perceberem as experiências comuns, ampliar a compreensão das dificuldades vivenciadas pelas mulheres, aprofundar o nível de comunicação dentro do grupo, possibilitar a expressão de sentimentos represados, ou demonstrar como estereótipos e interpretações subjetivas podem interferir na comunicação e nas percepções sobre outras pessoas. Aos poucos, foram articulando os temas entre si, sendo que cada subtema despertava interesse em aprofundar e buscar outros conhecimentos correlatos. As oficinas que trabalharam o tema da violência fizeram emergir muitas experiências dolorosas, que foram solidariamente acolhidas pelo grupo e equipe. Como relatado por Loira: "Quando meu marido fazia 'ignorância' [agressividade], eu me calava e fumava pra não ser
${ }^{4}$ Os nomes ficticios foram escolhidos pelas próprias mulheres, usando adjetivos que tivessem as iniciais de seus nomes. 
dois ignorantes. Me sentia triste". Como esta fala demonstra, as multiplicadoras foram gradativamente estabelecendo os fios que conectam todas as esferas da vida cotidiana ao tabagismo, superando a tradicional visão que hierarquiza os 'riscos' de forma mecânica e sem considerar outros aspectos da vida das pessoas. Tabagismo e gênero foram, assim, gradativamente se conectando e se consolidando como uma maneira de se perceber, considerar e compreender as dimensões de vida que estão associadas ao fumar, em especial, o fumar feminino.

Além das oficinas, diversas atividades externas foram programadas, visando corresponder aos anseios de aprendizagem do grupo e à crescente necessidade de ampliar seus horizontes de mundo para além das fronteiras da Maré.

A convivência frequente, a confiança mútua fortalecida, os temas mais íntimos compartilhados e debatidos durante as oficinas foram construindo coletivamente o 'rosto' e a identidade do grupo, além de ampliar a percepção de que 'sozinho não se faz nada'. Como percebido por Loira: "Pelo grupo é preciso ceder, mesmo que muitas vezes não seja de seu agrado". Estas vivências culminaram com o 'batismo' do grupo, que elegeu o nome 'Grupo Multiplicação: Mulheres pela Prevenção' e, posteriormente, criou um logo representativo para os materiais e camisetas usados por elas quando em atuação. Ao final da primeira etapa, o grupo foi estimulado a pensar sobre como realizar um trabalho de prevenção do tabagismo com as mulheres de sua comunidade. Daí emergiu o modelo educativo para as intervenções que elas viriam a desenvolver na etapa subsequente, de multiplicação.

\section{Entrando em campo:}

\section{(re)conhecendo o território, legitimando-se como 'multiplicadoras'}

Durante a segunda etapa do projeto, o grupo foi convidado a re-conhecer sua própria comunidade através de um olhar problematizador, que desnaturalizasse o cotidiano. Como protagonistas do processo de aprendizagem, passaram a percorrer a comunidade para melhor conhecerem sua realidade, agora com 'novos olhos'. Observaram o campo de pesquisa, perguntaram, conversaram, anotaram, descobriram notícias interessantes nos jornais comunitários. Ao retornarem ao grupo com os resultados de suas observações, traziam muitas dúvidas e reflexões. Em grupo, mais uma vez, tudo era discutido, anotado, sistematizado: um breve perfil desta realidade, elaborado coletivamente, começava a se delinear! Atribuíam um grau de importância ao que observavam, em geral dado pela percepção da frequência com que ocorria, chegando, inclusive, a identificarem aspectos até então desconhecidos em sua comunidade, como 'ninguém sabe o que é fumo passivo' ou 'os comerciantes locais vendem cigarros pra qualquer pessoa, até para as crianças'. As multiplicadoras, com o apoio da equipe, elaboraram, então, um diagnóstico situacional do tabagismo feminino na comunidade por meio de um questionário elaborado a partir de suas observações e vivências. Para a aplicação, dividiram-se em duplas, pois, dessa forma, se sentiam mais seguras. Sempre que retornavam à sala, tudo era debatido e as dificuldades, explicitadas. Loira, por exemplo, avaliou seu primeiro questionário como "uma tortura", pois se sentiu 'muito mal'. Mas, ao chegar em casa, acalmou-se e disse para si mesma: 'sou capaz', descobrindo uma autoconfiança que até então desconhecia. Assim, à medida que foram ganhando experiência e segurança, conseguiram aplicar o questionário entre 215 mulheres tabagistas moradoras de diversos bairros do entorno. Após a aplicação, respondiam às perguntas, dúvidas e ouviam desabafos das mulheres respondentes.

Perceberam, então, que a aplicação do questionário propiciava um espaço importante para transmitirem informações e começarem a estabelecer relações com as mulheres da comunidade. Para aproveitarem a oportunidade da abordagem de pesquisa, produziram um panfleto com dez frases significativas sobre o tabagismo, redigidas em uma linguagem simples e direta, que entregavam às pessoas logo após o término do questionário. Serena, ao falar sobre essa atividade, relatou sentir-se muito bem, como exfumante, em poder transmitir conhecimentos tão valiosos para as pessoas de sua vizinhança. Como visto, elas aprenderam a aproveitar toda e qualquer oportunidade do seu cotidiano para abordar a população e levar sua 'mensagem' de saúde.

Nesta segunda etapa, o grupo também percorreu a comunidade com o objetivo de identificar possíveis parcerias de trabalho. Motivadas pela equipe a organizarem e planejarem o trabalho, estabeleceram contatos preliminares, identificaram lideranças e as características de cada local 
contactado, como: espaço físico, equipamentos disponíveis, dias e horários para atividades, grupos-alvo. Sempre que retornavam das atividades de exploração do campo, eram incentivadas a refletir sobre os fenômenos observados e suas possíveis causas. A facilitadora sistematizava os relatos e complementava com outras informações necessárias, além de anotar as propostas de intervenção que começavam a emergir do grupo. Desta forma, em um processo de reflexão e troca de conhecimentos, faziam uma leitura de seu mundo e começavam a delinear estratégias que consideravam adequadas para sua realidade. Nesta etapa, foram mantidos os dois encontros semanais com a equipe, que, além de lhes dar apoio logístico para a entrada em campo, infundia-Ihes confiança na sua capacidade de realizarem o trabalho proposto.

Para legitimar sua atuação enquanto promotoras de saúde na prevenção do tabagismo em sua comunidade e encerrar a etapa de capacitação, a equipe apresentou, ao grupo, a proposta de realização de uma 'festa de formatura'5. Foi inestimável a importância deste ato simbólico em suas vidas, tão marcadas por dificuldades de acesso ao ensino e à capacitação profissional: seus familiares compareceram em peso à cerimônia - filhos (as) netos (as), companheiros, irmãos (ãs), mães, amigos (as) - e, também muito emocionados, expressaram sua surpresa ao perceberem, naquele momento, a 'grandeza' do trabalho para o qual elas haviam sido capacitadas. Agora, já (re)conhecidas na comunidade e legitimadas como 'as multiplicadoras', as mulheres prepararam-se, então, para partirem para a ação!

\section{Atuando no campo: enfrentando os desafios e construindo um modelo de intervenção educativa}

Nesta terceira e última etapa, o grupo retornou às instituições já cadastradas, agora já investidas da nova identidade - "Grupo Multiplicação: Mulheres pela Prevenção" -, trabalhando o fortalecimento dos laços já criados com os espaços de educação, saúde e de atividades culturais e de lazer da comunidade, com o intuito de atuar de forma integrada na prevenção e no estímulo à cessação do tabagismo.

Durante as oficinas com a equipe, iniciou-se o movimento de elaborar/ planejar as atividades que desejavam propor às parcerias. Neste momento, surgiram algumas dificuldades, já que muitas questões estavam em jogo: o tempo total de atividade, o local onde seria realizado, os recursos pedagógicos com que poderiam contar, o público-alvo da atividade, os temas correlatos a serem trabalhados, a escolha das dinâmicas e o preparo do material, entre outros. "Eu não consegui completar os quatro (planejamentos das dinâmicas) porque eu tinha dúvidas. Isso aí tá difícil...", como expressou Jeitosa. Nestes momentos, se fortalecia o clima de colaboração entre o grupo: as dificuldades iam sendo superadas coletivamente, na medida em que cada uma ajudava as outras nos quesitos nos quais tinha melhor domínio. Conquistando gradativamente segurança e autonomia, e com o acompanhamento, estímulo e suporte da equipe, foram se firmando. Dessa forma, neste processo de altos e baixos, e tendo de superar cotidianamente o medo e a insegurança, foram elaborando coletivamente seu próprio modelo de intervenção, adequando-o à realidade de vida local e aprendendo a escolher, com segurança crescente, os conteúdos das atividades de multiplicação e a metodologia que deveria ser adotada em cada situação/ contexto, quer fossem palestras, oficinas, dinâmicas de grupo, exibição de materiais educativos, visitas, reuniões ou exibição de filmes.

É, então, a partir desta terceira etapa, que as multiplicadoras organizaram, de forma mais sistemática, diversas atividades coletivas de sensibilização e envolvimento da comunidade na questão do tabagismo, como, por exemplo, a mobilização para as Campanhas do 31 de Maio - Dia Mundial Sem Tabaco - e de 29 de Agosto - Dia

\author{
${ }^{5} \mathrm{Na}$ formatura \\ foram entregues \\ diplomas \\ 'simbólicos', já que \\ este tipo de \\ capacitação não tem \\ reconhecimento \\ legal pelo \\ Ministério de \\ Educação.
}


Nacional de Combate ao Fumo. Além das oficinas nos locais de parceria estabelecidos anteriormente, formaram grupos reflexivos em suas próprias residências, além de fazerem visitas às casas de moradores que sabiam precisar de ajuda e estímulo. As tardes passaram a ser dedicadas a encontros com parentes, vizinhas e amigas, que elas chamavam de 'Chá da Alegria', 'Chá do Futuro', 'Chá Maravilhoso' etc... Como em todo trabalho, encontraram receptividade e reconhecimento, mas esbarraram em dificuldades, que as ensinavam, na prática, a improvisar, a criar, a usar o 'jogo de cintura'. Mais do que planejar as dinâmicas, as multiplicadoras, agora, percebiam que precisavam exercitar qualidades importantes para lidar com as pessoas com quem atuam, tais como: "ter paciência, ser comunicativa, alegre, saber favorecer o diálogo, respeitar o próximo e colocar-se no lugar do outro, chegar devagar, com jeito, com humildade, para poder conquistar o outro", como colocado por Loira. Jeitosa completou que "não adianta chegar sem paciência, chegar com panfleto e sem acolhimento". Já Maravilhosa acrescentou que se devia evitar, logo de início, "falar na doença ou que precisa parar de fumar". Perceberam, também, o valor do atributo de ouvir e de acolher, como colocado por Amada, antes muito falante: "Achei isso maravilhoso! Ver a história parecida com a minha e ficar calada, associar e ficar quieta". Maravilhosa também destacou o importante aprendizado de ouvir sem interferir: "Difícil segurar calada, sem perguntar, sem debater". O grupo começava a se sentir gratificado pelo trabalho desenvolvido. Jeitosa, animada, afirmou esperar que o trabalho "ajude as pessoas saberem que podem mudar". Já Amada disse esperar que lembrem dela como "a pessoa que levou informações, que ajudou.... Isto dá satisfação, alegria."

A duração desta etapa foi de sete meses, com um encontro semanal de quatro horas de supervisão para as atividades que se desenrolavam no campo. Em geral, a intervenção educativa era protagonizada em duplas. As mulheres logo perceberam que as atividades deveriam ser reflexivas e que o cuidado de evitar falar diretamente sobre doenças era fundamental. Ou seja, o modelo educativo freireano baseado na reflexão, diálogo, compartilhamento e busca coletiva de alternativas mais saudáveis de vida foi plenamente compreendido e internalizado por elas. Desta forma, superando a 'educação bancária' baseada na transmissão vertical do conhecimento, as mulheres passaram a organizar oficinas inspiradas nas dinâmicas pedagógicas vivenciadas na fase de capacitação, quando o ensinar-aprender-ouvirdialogar foi sendo gradativamente introjetado. Perceberam, também, a importância de desenvolverem atividades educativas com um 'toque' lúdico de animação e muito acolhimento para facilitar a aproximação e o interesse das mulheres. Esmeravam-se em preparar os planejamentos das oficinas, embora, no início, esta tenha sido uma atividade difícil, pois o planejamento escrito não faz parte do repertório escolar e cultural da população. Além disso, compreenderam a importância de preparar materiais educativos adequados para cada contexto, quando 'bolavam' dinâmicas próprias, sendo que aprenderam rapidamente a mudar as atividades quando percebiam que o trabalho não estava funcionando adequadamente durante uma oficina.

Dos primeiros passos, ao implementarem ações consideradas válidas para a problemática do tabagismo na comunidade, emergiram diversas emoções: medo de não estarem preparadas, de terem de se colocar em público, e a percepção de que, por mais que se preparassem, sempre havia imprevistos. De volta à reflexão no grupo, a viabilidade da ação desenvolvida era sempre avaliada por todas. Já sabiam que a avaliação de cada atividade é importante para se aprender com aquilo que não funcionou bem e redirecionar as ações para as próximas etapas.

Além do grupo-alvo feminino, foco principal do projeto, as multiplicadoras alargaram o alcance de sua intervenção, alcançando homens, jovens e crianças, na medida em que as parcerias iam incluindo escolas, igrejas, associações, grupos de alcoólicos anônimos (AA), e praças públicas, entre outros. $O$ primeiro trabalho desenvolvido com um grupo de homens foi realizado em uma reunião de Alcoólicos Anônimos (AA), em uma igreja local. Este foi um passo importante, já que, muitas vezes, estas pessoas, lutando contra o álcool, não consideram o cigarro como uma dependência.

O primeiro trabalho desenvolvido com jovens de uma escola pública local deixou marcas - frustração e sensação de não serem capazes de realizar o proposto - e um grande aprendizado 'freireano', já que é com a avaliação dos erros que se avança. Durante a supervisão desta atividade 'frustrada', o grupo acompanhou, com muita atenção e solidariedade, o relato da oficina, debatendo cada aspecto e buscando identificar os problemas ocorridos. Esta experiência serviu de exemplo e ensinamento para 
que outras atividades desenvolvidas posteriormente com outros jovens e crianças de diferentes escolas fossem muito mais proveitosas.

Outro aporte educativo que se revelou muito proveitoso foi a criação de uma peça teatral que trata com humor e ironia o tabagismo - intitulada Trago a Trago -, criada coletivamente pelas multiplicadoras, com a assessoria de uma educadora teatral, e cujo roteiro foi inspirado em suas vivências pessoais com o tabagismo. Essa peça passou a ser regularmente apresentada nas reuniões de recepção aos novos integrantes dos grupos para o tratamento de cessação, e em outros eventos para os quais eram convidadas, servindo como estratégia de sensibilização.

Ao final de um ano de atuação, as multiplicadoras realizaram 88 oficinas, sensibilizando diretamente duas mil, trezentos e sessenta pessoas - de ambos os sexos e diferentes faixas etárias - através de um processo dialógico e relacional. Os ganhos qualitativos e pedagógicos deste rico processo são incomensuráveis, pois demonstram quanto o saber científico se enriquece e se alarga quando dialoga com o saber popular. Essas questões ficaram evidentes quando, por exemplo, as multiplicadoras perceberam que deviam se aproximar das mulheres com uma mensagem de vida e saúde. Ou seja, rapidamente compreenderam que o discurso focado no 'perigo' da doença, ao invés de atrair, geralmente afasta as pessoas do trabalho educativo, superando, assim, os tradicionais modelos educativos 'bancários', que têm se mostrado tão ineficazes. Nas palavras de Amada e Jeitosa:

"Houve uma mudança essencial, que facilitará em 50\% da abordagem, que é o fato de termos parado de falar de doença e de tabagismo e começar a falar de "Saúde da Mulher'". (Amada)

"Não chegar falando do cigarro, pra não gerar constrangimento". (Jeitosa)

\section{Considerações finais}

Como os resultados apresentados evidenciaram, as ações educativas dialógicas, baseadas em metodologias participativas e no reconhecimento e acolhimento das dimensões socioeconômicas, culturais e subjetivas que envolvem o cuidado em saúde, vêm mostrando-se mais eficazes, resolutivas e duradouras do que as tradicionais medidas 'verticalizadas', elaboradas com base apenas em saberes técnicos e racionais. Além disso, na perspectiva conceitual e metodológica proposta, o conhecimento que resulta do diálogo entre o saber técnico-profissional e o saber popular pode embasar a produção de materiais educativos relacionados às doenças crônicas que valorizam a participação dos usuários e o diálogo com os saberes das comunidades.

Como mostrou a trajetória do feminismo, quando as mulheres se reúnem para refletir, debater e compartilhar suas experiências de vida, fortalecem sua capacidade de compreensão crítica sobre a sociedade em que vivem(os) - ainda perpassada por profundas desigualdades, sociais e de gênero -, o que impulsiona a busca individual e coletiva de estratégias de superação das iniquidades e injustiças que as mulheres ainda enfrentam no seu cotidiano. Assim, não dissociar a abordagem do tabagismo da compreensão dos contextos de vida das mulheres, especialmente as que vivem em situações de vulnerabilidade social e violência, está em acordo com os princípios do PAISM, que preconiza a integralidade na assistência à saúde das mulheres e o fortalecimento de sua autonomia na conquista de seus direitos de cidadania.

Outra questão a se destacar foi o reconhecimento do trabalho das multiplicadoras pela comunidade, o que fortaleceu a autonomia/ cidadania dessas mulheres. "Nós somos pioneiras", orgulhosamente afirmou Loira. Legitimadas na/pela comunidade, pelo importante trabalho educativo desenvolvido, não podem mais sair à rua sem serem procuradas para uma conversa, um pedido de ajuda ou o relato de uma vitória alcançada através de sua intervenção. Esta atuação, capilar e cotidiana, as diferencia dos profissionais de saúde que trabalham na cessação, que não têm a inserção e a convivência no dia a dia da população, o que lhes permite um alcance inestimável. 
No plano individual e subjetivo, a vida das multiplicadoras mudou radicalmente. Algumas delas retomaram antigos planos e sonhos, como voltar a estudar. Com um elevado nível de motivação, aprenderam a refletir, a trabalhar em grupo, a teorizar com base em suas observações e raciocínio, a descobrir a própria criatividade, a se perceberem autônomas na busca de informações e nas ações empreendidas. Todas essas conquistas refletiram-se no fortalecimento de sua autoestima, o que trouxe substanciais mudanças, subjetivas e objetivas, como aponta a fala de Jeitosa: "A gente não tem que se diminuir porque não tem estudo. Eles (os moradores da comunidade) sabem de onde a gente veio e o grau de estudo que a gente tem. Não tem que se sentir envergonhada". Essa percepção confirma quanto o saber popular, quando reconhecido e valorizado pela própria população, pode representar uma importante contribuição para as estratégias de promoção da saúde.

No plano comunitário, os inúmeros convites que passaram a receber de diversos profissionais de saúde e educação, além do explícito reconhecimento da comunidade, evidenciam quanto a pedagogia conscientizadora e dialógica possibilita a realização de um trabalho educativo transformador, confirmando a importância de se considerarem as dimensões culturais e subjetivas na promoção da saúde. Como colocado por Loira, "Eu não tinha noção... eu não tinha noção do que a gente poderia proporcionar pra humanidade... muita coisa... pra grandes (adultos) e pequenos (crianças)!"

\section{Colaboradores}

As autoras trabalharam juntas em todas as etapas de produção do manuscrito, desde sua elaboração até a revisão do texto.

\section{Referências}

BARBOSA, R.; BORGES, M. Tabagismo feminino em um enfoque de gênero: construindo um modelo de intervenção para a abordagem do tabagismo em espaço populares. 2009-2011. (Pesquisa-ação). Rio de Janeiro: Instituto de Estudos de Saúde Coletiva, Universidade Federal do Rio de Janeiro. 2009-2011.

BORGES, M.T.T. Tabagismo em mulheres: as marcas de gênero no fumar feminino. 2007. Dissertação (Mestrado) - Instituto de Estudos em Saúde Coletiva, Universidade Federal do Rio de Janeiro, Rio de Janeiro. 2007.

BORGES, M.T.T.; BARBOSA, R.H.S. As marcas de gênero no fumar feminino: uma aproximação sociológica do tabagismo em mulheres. Cienc. Saude Colet., v.14, n.4, p.1129-39, 2009. Disponível em: <http://www.scielo.br/scielo.php?script=sci arttext\&pid $=S 1413-81232009000400019 \& \operatorname{lng}=p t \& n r m=i s o>$. Acesso em: $2 \overline{6}$ jun. 2012.

BORGES, M.T.T.; SIMÕES-BARBOSA, R.H. Cigarro "companheiro": o tabagismo feminino em uma abordagem crítica de gênero. Cad. Saude Publica, v.24, n.12, p.2834-42, 2008. Disponível em: <http://www.scielo.br/scielo.php?script=sci arttext\&pid=S0102-311X2008001200012\&lng =pt\&nrm=iso >. Acesso em: $\overline{2} 6$ jun. 2013.

BRASIL. Ministério do Planejamento, Orçamento e Gestão. Instituto Brasileiro de Geografia e Estatística. Pesquisa nacional por amostra de domicílios: tabagismo 2008. Disponível em: <http://www.ibge.gov.br/home/estatistica/população/ trabalhoerendimento/pnad2008/suplementos/tabagismo/pnad_tabagismo.pdf > . Acesso em: 17 fev. 2011. 
BRITO, J.C. Enfoque de gênero e relação saúde/trabalho no contexto de reestruturação produtiva e precarização do trabalho. Cad. Saude Publica, v.16, n.1, p.195-204, 2000. Disponível em: <http://www.scielo.br/scielo.php?script=sci_arttext\&pid=S0102$311 \times 2000000100020 \& \operatorname{lng}=$ pt\&nrm=isso >. Acesso em: 26 jun. 2012.

CARVALHO, M.A.P.; ACIOLI, S.; STOTZ, E.N. O processo de construção compartilhada do conhecimento: uma experiência de investigação científica do ponto de vista popular. In: VASCONCELOS, E. (Org.). A saúde nas palavras e nos gestos. São Paulo: Hucitec, 2001. p.101-14.

CASTRO, M.G. Marxismo, feminismos e feminismo marxista: mais que um gênero em tempos neoliberais. Crit. Marx., n.11, p.98-108, 2000.

COSTA, A.M.; AQUINO, E.L. Saúde da Mulher na Reforma Sanitária Brasileira In: COSTA, A.M.; MERCHÁN-HAMANN, E.; TAJER, D. (Orgs.). Saúde e equidade de gênero: um desafio para as políticas públicas. Brasília: Abrasco, Alames, UnB, 2000. p.181-202.

DAVID, H.M.S.L.; ACIOLI, S. Mudanças na formação e no trabalho de enfermagem: uma perspectiva da educação popular e de saúde. Rev. Bras. Enferm., v.63, n.1, p.127-31, 2010. Disponível em: <http://www.scielo.br/scielo.php?script=sci_arttext\& pid $=$ S0034-71672010000100021\&lng $=$ pt\&nrm =iso >. Acesso em: 26 jun. 2013.

FREIRE, P. Pedagogia do oprimido. 48.ed. Rio de Janeiro: Paz e Terra, 2009.

Pedagogia da autonomia: saberes necessários à prática educativa. 19.ed. São Paulo: Paz e Terra, 1996.

FREIRE, P.; FAUNDEZ, A. Por uma pedagogia da pergunta. Rio de Janeiro: Paz e Terra, 1985.

GIFFIN, K. Pobreza, desigualdade e equidade em saúde: considerações a partir de uma perspectiva de gênero transversal. Cad. Saude Pub., v.18, supl., p.103-12, 2002. Disponível em: <http://www.scielo.br/scielo.php?script=sci_arttext\&pid=S0102$311 \times 2002000700011 \& \operatorname{lng}=p t \& n r m=$ iso $>$. Acesso em: $26^{-}$jun. 2013.

Estudos de gênero e saúde coletiva: teoria e prática. Saude Debate, v.46, p.29-33, 1995

GIFFIN, K.M.; SIMÕES BARBOSA, R.H. Sujeitos do conhecimento/do gênero. In: MARTELETO, R.M.; STOTZ, E.N. (Orgs.). Informação, saúde e redes sociais: diálogos de conhecimentos nas comunidades da Maré. Rio de Janeiro: Fiocruz, 2009. p.65-82.

KERGOAT, D. Relações sociais de sexo e divisão sexual do trabalho. In: LOPES, M.J.; MEYER, D.E.; WALDOW, V.R. (Orgs.). Gênero e saúde. Porto Alegre: Artes Médicas, 1996. p.19-27.

OSIS, M.J.M.D. PAISM: um marco na abordagem da saúde reprodutiva no Brasil. Cad. Saude Publ., v.14, supl.1, p.25-32, 1998. Disponível em: <http://www.scielo.br/ scielo.php?script $=$ sci_arttext $\&$ pid $=$ S0102-311X1998000500011\&lng $=p t \& n r m=i s o>$. Acesso em: 26 jun.2013.

REASON, P. Three approaches to qualitative inquiry. In: DENZIN, N. (Org.). Handbook of qualitative research. Thousand Oaks: Sage, 1994. p.324-39.

SAFFIOTI, H.I.B. Rearticulando gênero e classe social. In: COSTA, A.O; BRUSCHINI, C. (Orgs.). Uma questão de gênero. Rio de Janeiro: Rosa dos Tempos, 1992. p.183-215.

SHAFEY, O. et al. The tobacco atlas. 3.ed. Atlanta: American Cancer Society, 2009.

SIMÕES BARBOSA, R.H. Mulheres, reprodução e aids: as tramas da ideologia na assistência à saúde de gestantes HIV+. 2001. Tese (Doutorado) - Escola Nacional de Saúde Pública, Fundação Oswaldo Cruz, Rio de Janeiro. 2001a. 
SIMÕES BARBOSA, R.H. Educação e saúde reprodutiva: análise preliminar de uma experiência numa comunidade favelada do Rio de Janeiro. In: SILVA, D.P.M. (Org.). Sexualidade em diferentes enfoques: uma experiência de capacitação no campo da saúde reprodutiva. Niterói: Muiraquitã, PEGGE/UERJ, 2001b. p.123-31.

SIMÕES BARBOSA, R.H.; GIFFIN, K. Gênero, saúde reprodutiva e vida cotidiana em uma experiência de pesquisa-ação com jovens da Maré, Rio de Janeiro. Interface (Botucatu), v.11, n.23, p.549-67, 2007. Disponível em: <http://www.scielo.br/scielo.php?script= sci_arttext\&pid=S1414-32832007000300011\&lng=pt\&nrm=iso > . Acesso em: 26 jun. 2013.

VALADARES, D.; SANCHES, S.; GIFFIN, K. Mulheres, participação e saúde. Rio de Janeiro: FLACSO/Unicef/CNDM, 1987

VALLA, V.V. Procurando compreender a fala das classes populares. In: VALLA, V.V.; ALGEBAILE, E.; GUIMARÃES, M.B. (Orgs.). Classes populares no Brasil: exercícios de compreensão. Rio de Janeiro: Fiocruz, 2011. p.91-103.

VASCONCELOS, E.M. Educação popular: instrumento de gestão participativa dos serviços de saúde. In: BRASIL. Ministério da Saúde. Secretaria de Gestão Estratégica e Participativa. Departamento de Apoio à Gestão Participativa. Caderno de educação popular e saúde. Brasília: MS, 2007. (Serie B, Textos Básicos de Saúde). Disponível em: <http://portal.saude.gov.br/portal/arquivos/pdf caderno_de_educacao_popular_e_ saude.pdf $>$. Acesso em: 26 jun. 2013.

. Educação popular: de uma prática alternativa a uma estratégia de gestão participativa das políticas de saúde. Physis, v.14, n.1, p.67-83, 2004. Disponível em: $<$ http://www.scielo.br/scielo.php?script=sci_arttext\&pid=S0103-

73312004000100005\&lng=pt\&nrm=iso>. Acesso em: 26 jun. 2013.

. Educação popular como instrumento de reorientação das estratégias de controle das doenças infecciosas e parasitárias. Cad. Saude Publica, v.14, supl.2, p.39-57, 1998. Disponível em: <http://www.scielo.br/scielo.php?script=sci_arttext\& pid=S0102-311X1998000600004\&lng=pt\&nrm=iso >. Acesso em: 26 jun. 2013.

WORLD HEALTH ORGANIZATION. Report on the global tobacco epidemic, 2009. Disponível em: <http://whqlibdoc.who.int/hq/2009/WHO_NMH_TFI_09. 1_eng.pdf>. Acesso em: 26 jun. 2013.

WUNSCH FILHO, V. et al. Tabagismo e câncer no Brasil: evidências e perspectivas. Rev. Bras. Epidemiol., v.13, n.2, p.175-87, 2010. Disponível em: <http://www.scielo.br/ scielo.php?script $=$ sci_arttext\&pid $=$ S1415-790X2010000200001\&lng $=$ en \& $\mathrm{nrm}=$ iso $>$. Acesso em: 26 jun. 2013.

XAVIER, D.; ÁVILA, M.B.; CORREA, S. Questões feministas para a ordem médica: o feminismo e o conceito de saúde integral. In: LABRA, M.E. (Org.). Mulher, saúde e sociedade. Rio de Janeiro: Vozes, 1989. p.203-22. 
BORGES, M.T.T.; BARBOSA, R.H.S. Convergencia de género y educación popular por medio de una investigación-acción para el abordaje del tabaquismo femenino en contextos de vulnerabilidad social. Interface (Botucatu), v.17, n.46, p.601-14, jul./set. 2013.

Este artículo presenta los resultados de una investigación-acción (IA) sobre el tabaquismo femenino en espacios populares. La propuesta se originó del diálogo entre los campos conceptuales y metodológicos provenientes del feminismo y de la educación popular y su objetivo fue comprender las cuestiones subjetivas y objetivas del universo femenino relacionadas con el acto de fumar, tanto en el ámbito familiar como en el social y comunitario. La IA capacitó a seis mujeres de una comunidad popular de Río de Janeiro, Brasil, ex tabaquistas, para que desarrollaran un proceso educativo que incluyó a mujeres, hombres y niños de una forma dialogada y participativa. Los resultados revelan cómo se construye, a través de la praxis educativa dialógica, un conocimiento compartido sobre la salud, resultante de una integración del conocimiento académico y del saber popular, confirmando el potencial de esta propuesta para combatir el tabaquismo femenino en los contextos populares.

Palabras clave: Hábito de fumar. Identidade de énero. Educación popular. Investigación-acción. 